\title{
Dyke demolition led to a sharp decline in waterbird diversity due to reduction in habitat quality: A case study of Dongting Lake, China
}

\author{
Feng Zhu ${ }^{1}$, Ye-ai Zou ${ }^{2}$, Pingyang Zhang ${ }^{2}$, Siqi Zhang ${ }^{2}$, Xinsheng Chen ${ }^{2}$, Feng Li $^{2}$, \\ Zhengmiao Deng ${ }^{2}$, Hong Zhang ${ }^{3}$, Zhibing $\mathrm{Yu}^{3}$, Xiaoyong $\mathrm{Zhu}^{3}$, Yonghong $\mathrm{Xie}^{2}$, and \\ Dongsheng Zou ${ }^{1}$ \\ ${ }^{1}$ Hunan Agricultural University \\ ${ }^{2}$ Institute of Subtropical Agriculture Chinese Academy of Sciences \\ ${ }^{3}$ Administrative Bureau of Hunan East Dongting Lake National Nature Reserve
}

November 3, 2021

\begin{abstract}
Waterbird responses to habitat changes are of great concern in ecology. Dongting Lake is the second-largest freshwater lake in China, and its vast wetland area provides an important wintering habitat for migratory waterbirds of the East AsianAustralasian Flyway. However, lake reclamation and illegal human-made dykes have degraded the Dongting Lake wetland area at different degrees in the recent decades, seriously threatening the ecology of this area. In 2017, to restore the natural properties of Dongting Lake, the Chinese government completely demolished 459 dykes and preserved 14 dykes for various purposes (biodiversity conservation and flood control). However, the direct impact of dyke demolition on wintering waterbirds has not been comprehensively assessed. In this study, based on annual (2013/14-2020/21) waterbird census data, we compared the differences in species composition of waterbirds in the dyke-demolished and dyke-preserved areas. The results indicated that waterbird diversity, in terms of species number, abundance, the proportion of abundance, number of rare waterbirds species, and exclusive species, was higher in the dyke preserved areas than in the previously demolished areas. Species turnover and reordering further identified dynamic differences in the spatial and temporal distributions of waterbirds. Therefore, we used long-term habitat data to explore whether habitat changes were responsible for the changes in waterbirds; the results showed significantly decreased water and mudflat areas, but a significantly increased vegetation area in the dyke-demolished areas. The water area was significantly positively correlated with waterbirds in this habitat. Compared to the dyke-demolished areas, the stable and suitable habitat area in the dyke-preserved areas might be closely related to the higher waterbird diversity. Our study revealed habitat changes in the context of large-scale dyke demolition in Dongting Lake and demonstrated the dynamic response of waterbirds to habitat changes.
\end{abstract}

\section{Hosted file}

Manuscript.docx available at https://authorea.com/users/444268/articles/544066-dykedemolition-led-to-a-sharp-decline-in-waterbird-diversity-due-to-reduction-in-habitatquality-a-case-study-of-dongting-lake-china 